\title{
Pharmaceutical advertising in magazines
}

$\mathrm{L}$ ast month I saw an elderly gentleman who woke up hemiplegic. The paramedics rushed him to our ED and, for reasons I can't remember, I managed to see him within 5 minutes of his arrival, even before the nurses had taken his vital signs. But as I was introducing myself, his wife rushed to the bedside, breathless, and demanded to know whether we had given him "the clot busting drug" yet. When I answered in the negative, she reddened angrily. "Well why are you dawdling?" she snapped. (This is a true story.)

I spent 10 minutes explaining why her husband was not a candidate for thrombolysis. Despite my efforts she was far from satisfied. She was not aware that tPA could cause brain hemorrhages and she thought I must be mistaken. "Surely they wouldn't treat strokes with a drug that causes strokes," she muttered.

Pharmaceutical companies advertise heavily in US lay magazines, and this marketing movement is coming to Canada. It won't be long before our patients arrive brandishing copies of
"You've seen your doctor?" You frown. "Why didn't you tell me?"

"He gave me this." Pflug removes a crumpled prescription from his pocket and tosses it on the bed. "Erythromycin!" he snorts derisively. "He doesn't know what he's doing."

"Erythromycin is good," you say. "It—",

"I want the best!" He pulls out a copy of Architectural Digest and points to the ad on the back. "I want Supermegacillin."

The ad is full-page colour, showing a weathered but obscenely healthy 80 year-old planting a flag on the summit of Everest. There's brilliant sunshine, an iridescent sky, and several beautiful female mountaineers gazing adoringly at the old man. The flag he's just planted has a picture of a teal-coloured tablet labelled 'Supermegacillin.' The bold black text at the bottom of the ad exclaims: "SUPERMEGACILLIN! 50\% BETTER IN PATIENTS WITH PNEUMONIA!"

"But Mr. Pflug," you say. "This is just an ad."

\section{Most physicians have a hard time critically appraising scientific literature, and patients don't have a chance.}

Harpers, Cosmo, or Dog and Kennel, demanding the latest miracle drug.

It will go something like this.

You approach your well-appearing patient with a prescription you've written for erythromycin. "I've looked at your X-ray, Mr. Pflug," you say. "You have community-acquired pneumonia."

Pflug eyes you suspiciously. "My doctor told me it's 'walking' pneumonia."

\author{
"They wouldn't lie." \\ "I read the study," you explain, "and \\ $50 \%$ doesn't refer to the cure rate. \\ They did multiple comparisons and \\ reported the only outcome that looked \\ better with their drug. 50\% refers to \\ the proportion of people who still had \\ coloured sputum on day 5 ." \\ " $50 \%$ is $50 \%$," he says, becoming \\ testy.
}

"It wasn't even an absolute reduc- tion. It was a relative reduction, from $2 \%$ to $1 \%$. And the confidence intervals overlap. It's not even statistically significant."

"You're as bad as my doctor." Pflug is getting angry.

"And worse!" you mutter. "The $50 \%$ comes from a subgroup analysis; the benefit was limited to unemployed male Norwegians under 60 inches tall who presented on Tuesdays with temperatures between 38.6 and 39.1 degrees. They were data dredging."

"Dredging schmedging," he curses. "I want Supermegacillin!"

"It costs 10 times as much."

"My insurance pays."

You throw your arms up. "More people died in the Supermegacillin group."

Pflug ponders you sadly and sighs. "Don't you doctors read? This was published in Motor Trend too. And on the Web." With this, he jumps to his feet and storms out of the department. "I'm going to a specialist."

Most physicians have a hard time critically appraising scientific literature, and patients don't have a chance. Unless your patients are primarily epidemiologists, they'll want the drug with the sexiest ad regardless of your explanations about multiple comparisons, unblinded outcome determination, retrospective subgroup analysis, and clinical versus statistical significance. More than ever, marketing, not evidence, will determine what care is delivered.

Drug marketing in lay magazines is a very questionable practice.

\section{Grant Innes, MD}

St. Paul's Hospital

Vancouver, BC

ginnes@interchange.ubc.ca 